Research Paper

\title{
MicroRNA-142-3p and let-7g Negatively Regulates Augmented IL-6 Production in Neonatal Polymorphonuclear Leukocytes
}

\author{
Hsin-Chun Huang1, 2, Hong-Ren Yu¹, Te-Yao Hsu³, I-Lun Chen ${ }^{1,4}$, Hui-Chen Huang1, Jen-Chieh Chang1, \\ and Kuender D. Yang ${ }^{5 凶}$
}

1. Department of Pediatrics, Kaohsiung Chang Gung Memorial Hospital and Chang Gung University College of Medicine, Kaohsiung 833, Kaohsiung, Taiwan

2. School of Traditional Chinese Medicine, College of Medicine, Chang Gung University, Linkou, Taiwan

3. Department of Obstetrics, Kaohsiung Chang Gung Memorial Hospital and Chang Gung University College of Medicine, Kaohsiung 833, Kaohsiung,

Taiwan

4. Graduate Institute of Medicine, College of Medicine, Kaohsiung Medical University, Kaohsiung, Taiwan

5. Department of Pediatrics, Mackay Memorial Hospital, Tamshui, Taiwan

6. Institute of Clinical Medical Sciences, National Yang Ming University, Taipei, Taiwan

$\square$ Corresponding author: Kuender D. Yang, MD, Ph.D., Professor, Mackay Memorial Hospital, Tamshui branch, No. 45, Minsheng Rd., Tamshui District, New Taipei City 25160, Taiwan Tel: +886-2-2809-4661 Fax: +886-2-2809-4679 E-mail: yangkd.yeh@hotmail.com, nbhhuang@icloud.com

(c) Ivyspring International Publisher. This is an open access article distributed under the terms of the Creative Commons Attribution (CC BY-NC) license (https://creativecommons.org/licenses/by-nc/4.0/). See http://ivyspring.com/terms for full terms and conditions.

Received: 2016.07.29; Accepted: 2017.03.13; Published: 2017.05.16

\begin{abstract}
Neonatal PMN are qualitatively impaired in functions, yet they frequently reveal augmented inflammatory reactions during sepsis. Here, we hypothesized that PMN from newborns produce more IL-6 than those from adults under LPS stimulation, in which transcriptional or posttranscriptional regulation is involved in the altered expression. We found that neonatal PMN produced significantly higher IL-6 mRNA and protein than adult PMN. The higher IL- 6 expression was not related to transcriptional but posttranscriptional regulation as the IL- 6 expression was affected by the addition of cycloheximide but not actinomycin. To examine whether miRNA was involved in the IL-6 regulation of neonatal PMN, we surveyed differential displays of miRNAs that could potentially regulate IL-6 expression before and after LPS stimulation. Four miRNAs: hsa-miR-26a, hsa-miR-26b, hsa-miR-142-3p and hsa-let 7g decreased or increased after LPS treatment for $4 \mathrm{~h}$. Further validation by $q R T-P C R$ identified miR-26b, miR-142-3p and let-7g significantly changed in neonatal PMN after LPS stimulation. The functional verification by transfection of miR-142-3p and let-7g precursors into neonatal PMN significantly repressed the IL-6 mRNA and protein expression, suggesting that miR-142-3p and let-7g negatively regulate IL-6 expression in neonatal PMNs. Modulation of miRNA expression may be used to regulate IL-6 production in newborns with altered inflammatory reactions.
\end{abstract}

Key words: miR-142-3p, let-7g, polymorphonuclear leukocytes, cord blood, IL-6, sepsis.

\section{Introduction}

Neonatal sepsis is still a major threat for infants, even with the development of antibiotics [1]. Upon bacterial infections, older children and adults are usually able to restrict infection spreading; however, neonates are susceptible to bacterial sepsis with a severe systemic inflammatory response with respiratory distress and/or bacterial meningitis. There is growing evidence that this process is crucially mediated by the action of proinflammatory cytokines, such as IL-1ß, IL-6, and TNF- $\alpha[2,3]$.

IL-6 is known to be a key component of
LPS-induced endotoxemia and sepsis $[4,5]$. However, expression of endogenous IL-6 can paradoxically reduce endotoxin-induced mortality. In addition to being an activator of acute phase responses, IL- 6 is also critical for regulating innate immunity and promoting adaptive immune responses [6, 7]. Recently, more studies suggested the therapeutic potential of targeting IL-6 in certain inflammatory processes $[8,9]$. With more understanding of IL-6 regulation, we might provide a better strategy to control altered inflammation of neonatal sepsis. 
Certain miRNAs have been demonstrated to regulate LPS-induced endogenous expression of IL-6 in mice model [8]. The region targeted by miRNAs in the 3' UTR of IL-6 mRNA is relatively conserved between humans and mice [10]. Thus, we make a hypothesis that PMN from newborns produce more IL-6 than those from adults under LPS stimulation, in which certain miRNA is involved in the altered expression of IL-6. To better characterize the mechanism of IL-6 expression by neonatal PMN, we screened the transcriptional and posttranscriptional regulation of IL- 6 between newborns and adults, and validated what miRNA is involved in the regulation by manipulating loss or gain of function on the miRNA that regulates IL- 6 expression between PMN from newborns and adults.

\section{Results}

\section{Neonatal PMN produced higher IL-6 than adult ones upon LPS stimulation}

First, we compared the IL- 6 production by CB and $A B$ PMN. Under resting condition, $C B$ and $A B$ PMN had similarly lower IL-6 production. Upon LPS stimulation, the IL-6 production was increased both in $\mathrm{CB}$ and $\mathrm{AB}$ PMN (Fig. 1A). However, CB PMN had higher LPS-induced IL-6 production than AB PMN after $6 \mathrm{~h}$ stimulation and reached its significant level after $24 \mathrm{~h}$ of stimulation $(p=0.03)$. Immunohistochemical staining of PMN for IL-6 expression also showed a similar result (Fig. 1B).

To identify whether LPS-induced IL-6 mRNA expression was compatible with IL-6 protein production, $\mathrm{AB}$ and $\mathrm{CB} P \mathrm{PMN}$ were stimulated with LPS and total RNA was extracted for IL-6 mRNA detection. As shown in Fig. 1C, CB PMN had significantly higher LPS-induced IL-6 mRNA expression than $\mathrm{AB}$ PMN after 4 and $6 \mathrm{~h}$ of stimulation.

\section{Neonatal and adult PMN exhibit different transcriptional and post-transcriptional regulation of IL-6 expression}

To explore the possible transcriptional or post-transcriptional regulation for the relatively higher IL-6 mRNA and protein expression in the CB $P M N$, we treated PMN from either $C B$ or $A B$ with 1 $\mu \mathrm{g} / \mathrm{mL}$ of Act-D to block mRNA synthesis for studying the mRNA half-life. As shown in Fig. 2A, neonatal and adult PMN had similar IL-6 mRNA half-life values, which were $82.4 \pm 6.1$ and $86.1 \pm 5.2 \mathrm{~min}$, respectively. It suggested that mRNA decay did not contribute to the IL-6 mRNA expression difference between $\mathrm{CB}$ and $\mathrm{AB}$ PMN. Subsequently, $\mathrm{CB}$ and $\mathrm{AB}$ $\mathrm{PMN}$ were treated with $\mathrm{CHX}$ for the indicated duration of time. As shown in Fig. 2B, $5 \mu \mathrm{g} / \mathrm{mL}$ of $\mathrm{CHX}$ treatment did not decrease the IL-6 protein level of either $\mathrm{CB}$ or $\mathrm{AB}$ PMN. However, with $\mathrm{CHX}$ treatment, $\mathrm{CB}$ PMN showed significantly higher LPS-induced IL-6 mRNA expression after $120 \mathrm{~min}$ of stimulation $(p=0.036)$, Fig. $2 \mathrm{C}$. Overall, it revealed the mechanism of higher LPS-induced IL-6 protein in neonatal PMN was regulated at the post-transcriptional level.
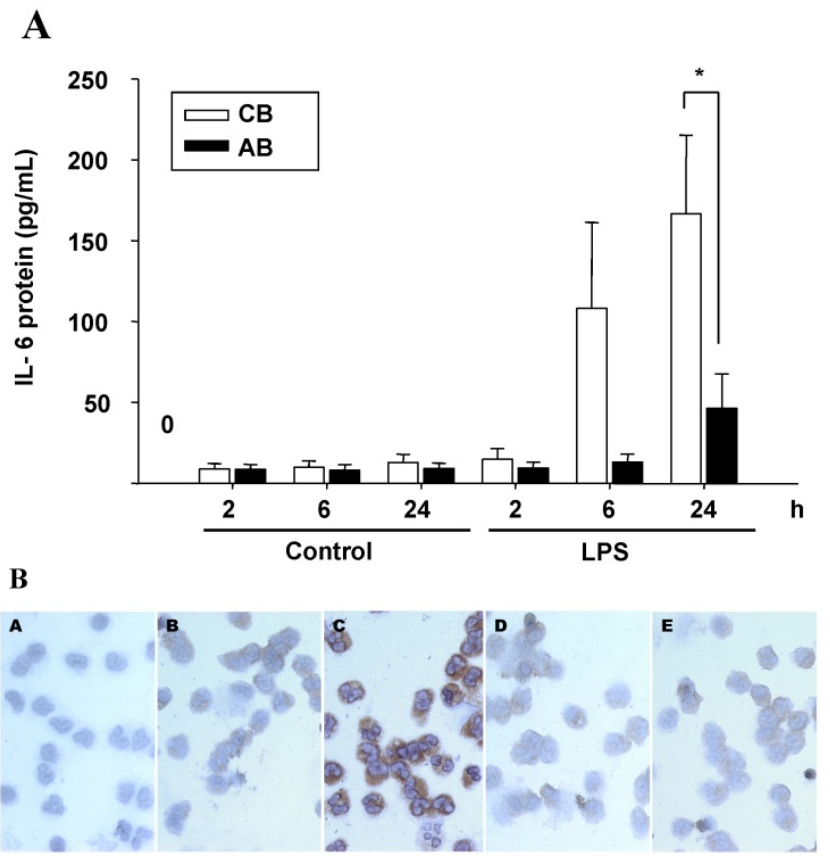

C

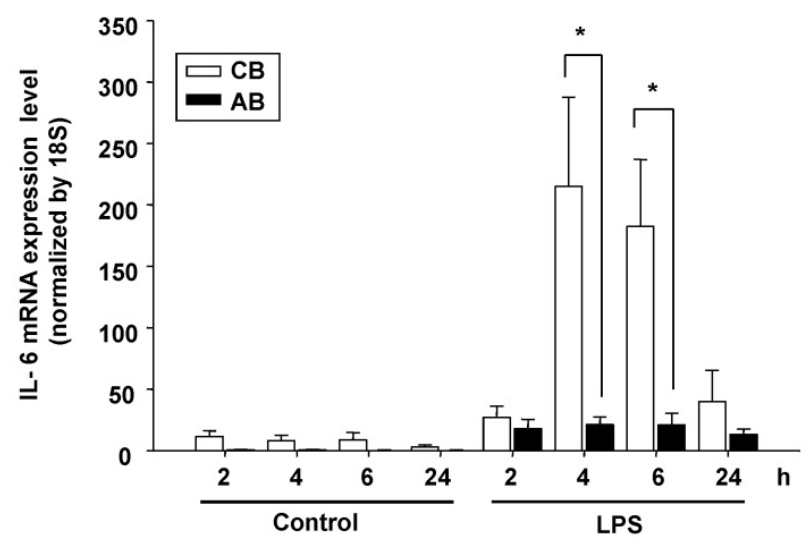

Figure 1. Neonatal PMN produced higher IL- 6 protein and mRNA than adult ones upon LPS stimulation. (A) PMN from cord blood and adult blood (labeled $C B$ and $A B$, respectively) were isolated and stimulated with $100 \mathrm{ng} / \mathrm{mL}$ of LPS. The culture supernatants were collected at 2, 6, and $24 \mathrm{~h}$ and detected for IL-6 production with ELISA. CB PMN had higher LPS-induced IL-6 production than adult ones. The data shown are mean \pm SEM from four independent experiments. (B) Immunohistochemical staining of PMN for IL-6 protein expression. A: negative control, $B$ : $C B$ without $L P S, C: C B$ with LPS, $D: A B$ without LPS, and $E: A B$ with LPS stimulation. Prominent IL-6 positive staining (brown colour) is found in CB PMN after LPS stimulation for $4 \mathrm{~h}$. (C) CB and $A B$ PMN were collected after LPS stimulation and indicated for IL-6 mRNA detection with qRT-PCR. Neonatal PMN had higher IL-6 mRNA expressions than adult ones upon LPS stimulation. The data shown are mean \pm SEM from four independent experiments. $*$ denotes $p<0.05$ 
A

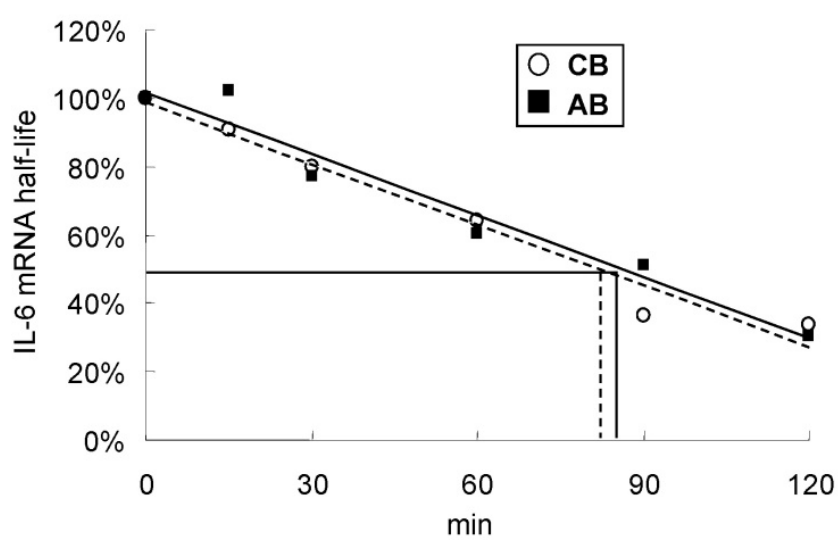

B

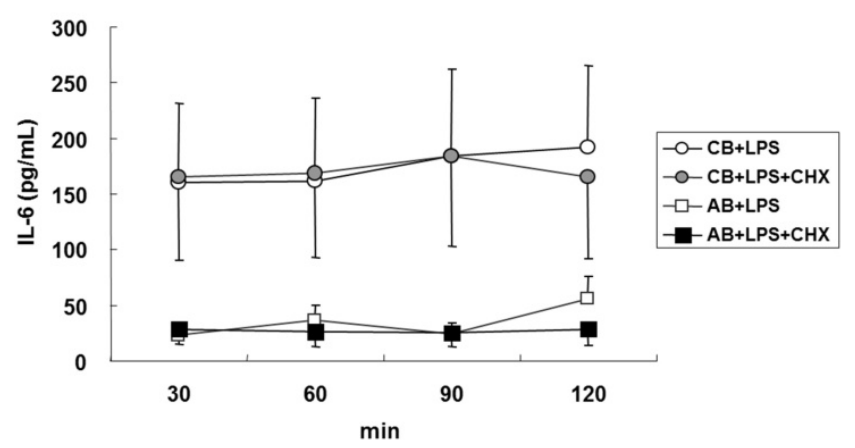

C

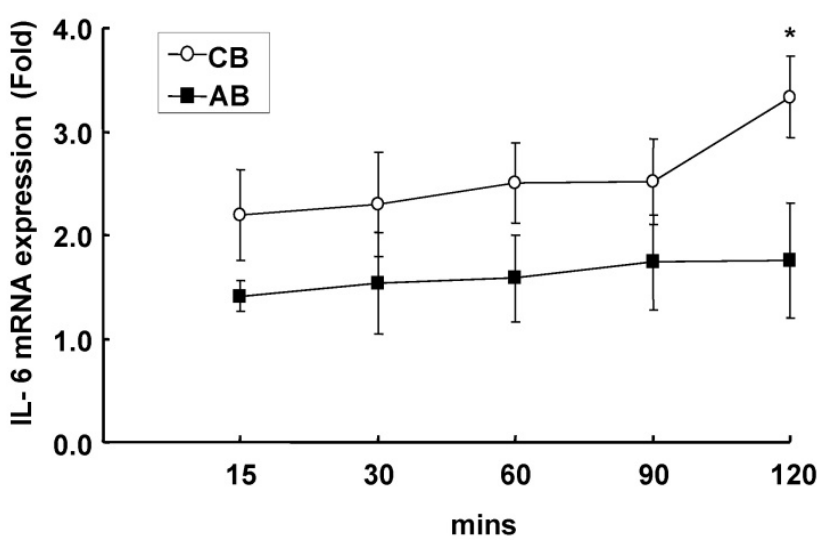

Figure 2. Neonatal and adult PMN exhibit different transcriptional and post-transcriptional regulation of IL-6 expression. (A) Cord blood (CB) and adult blood (AB) PMN were stimulated with LPS $(100 \mathrm{ng} / \mathrm{mL})$ for $4 \mathrm{~h}$ and then treated with actinomycin $D(1 \mu \mathrm{g} / \mathrm{mL})$ to block mRNA synthesis for studying the IL-6 mRNA half-life. Data are presented as the mean \pm SEM. Data from four independent experiments were averaged at each data point. The dashed lines show the calculated half-life for the IL-6 mRNA of neonatal PMN and solid lines show half-life of adult PMN, as indicated. In another independent study, PMN of $C B$ and $A B$ were stimulated with LPS $(100 \mathrm{ng} / \mathrm{mL})$ then treated with cycloheximide ( $5 \mu \mathrm{g} / \mathrm{mL} ; \mathrm{CHX}$ ) for 30 to $120 \mathrm{~min}$, as indicated. (B) Culture supernatants were subsequently prepared for ELISA analysis. (C) Cell pellets were prepared for IL-6 mRNA analysis with qRT-PCR. Results are representative of four independent experiments. * denotes $p<0.05$

\section{Profile of miRNAs expression induced by LPS between CB and AB PMN}

Further studies were then tried to demonstrate the role of miRNA in the post-transcriptional regulation of LPS-induced IL-6 expression. Using Illumina bead array, miRNAs expression in CB and $\mathrm{AB}$ PMN with and without LPS induction for $4 \mathrm{~h}$ were measured. Their data were integrated with the potential miRNAs which were identified from the miRanda, MicroCosm v5 and TargetScan v7.1 databases that target IL-6. There are 15 miRNAs related to the regulation of IL-6 gene expression (Fig. $3 \mathrm{~A}$ ). Four of the 15 miRNAs (hsa-let-7g, hsa-miR-26a, hsa-miR-26b, and hsa-miR-142-3p) were found to have decrease or increase significantly after LPS induction for $4 \mathrm{~h}$ (Fig. 3B). Experiments were later conducted to verify those 4 miRNAs expression by qRT-PCR. Level of let-7g and miR-26b increased significantly in adult PMN post LPS stimulation for 6 $\mathrm{h}$ as compare to $\mathrm{CB}, p=0.042$ and 0.02 respectively (Fig. 4A and 4B), whereas miR-142-3p increased significantly after 2, 6 and $24 \mathrm{~h}$ after LPS stimulation in adult PMN as compared to cord ones, $p=0.02$, 0.013, and 0.003, respectively (Fig. 4C). However, miR-26a was insignificantly changed with and without LPS stimulation between $\mathrm{CB}$ and $\mathrm{AB}$ PMN (Fig. 4 D). As let-7g, miR-26b and miR-142-3p changed significantly in $\mathrm{CB}$ and $\mathrm{AB}$ PMN after LPS-stimulation, therefore they were selected for transfection to validate their functions.

\section{miR-142-3p and let-7g supressed IL-6 mRNA and protein expression by PMN}

The mimics of let-7g, miR-26b or miR-142-3p were then transfected into $\mathrm{CB}$ and $\mathrm{AB} P M N$ as functional validation studies (Fig. 5A \& B). The viability of PMN after transfection was accessed and revealed no significant changes across various treatments, as shown in Fig. 5C. After transfection of miR-142-3p and let-7g mimics into PMN for $24 \mathrm{~h}$, LPS-induced IL-6 mRNA expression of both AB and CB PMN were supressed, $p<0.01$ for miR-142-3p (Fig. $5 \mathrm{D}) ; p=0.013$ for comparison of IL- 6 mRNA of $0 v$ s. 20 $\mathrm{nM}$ of let-7g M (mimics) transfection into cord PMN, and $p=0.044$ for adult PMN (Fig. 5E). Furthermore, LPS-induced IL-6 protein suppression effect of miR-142-3p mimics were significantly found on neonatal PMN, Fig. 5F. And let-7g mimics significantly suppressed IL-6 protein expression in cord and adult PMN post LPS stimulation, Fig. 5G. Nevertheless, transfection of miR-26b mimics did not suppress IL-6 mRNA and protein expression. 


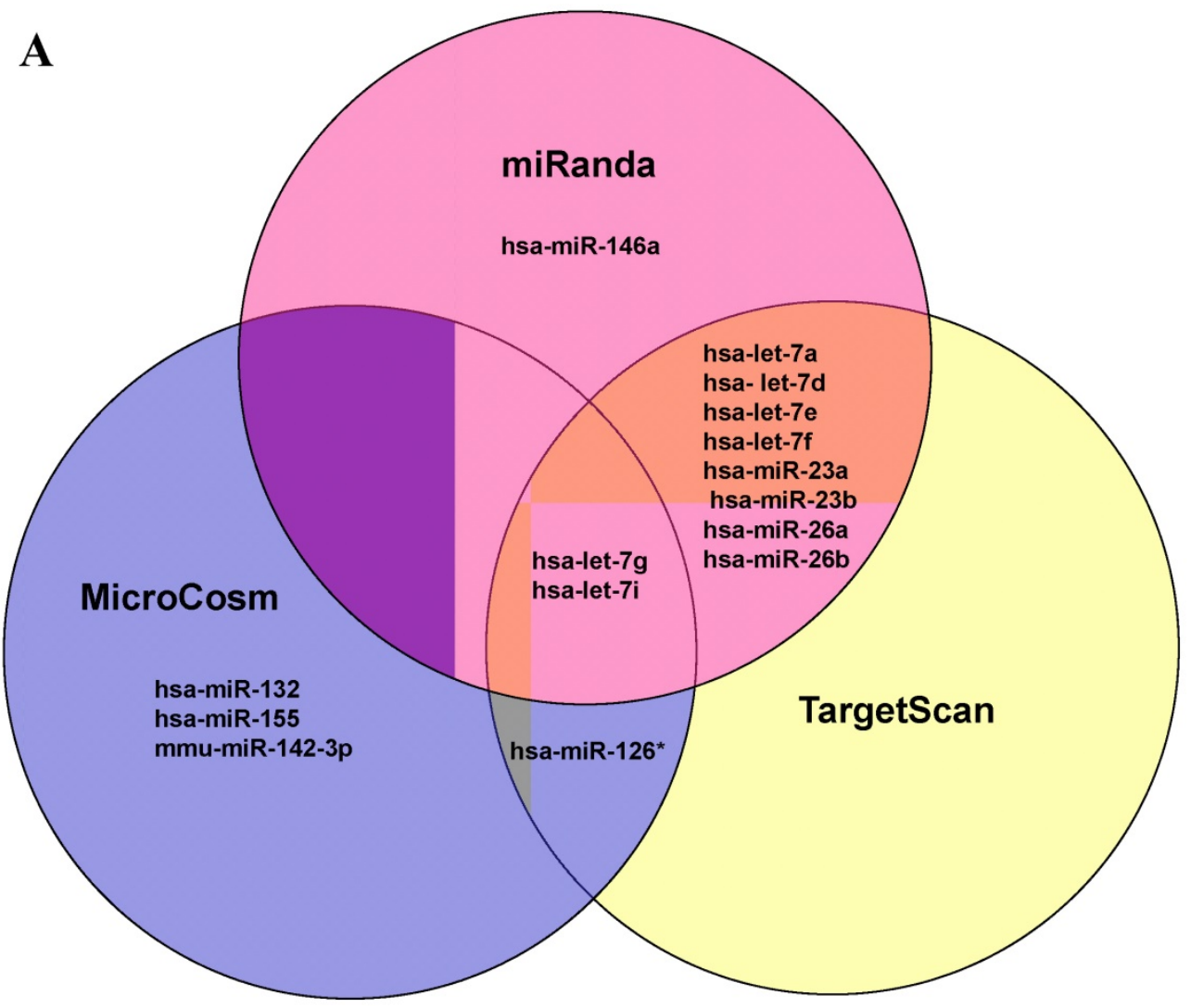

B
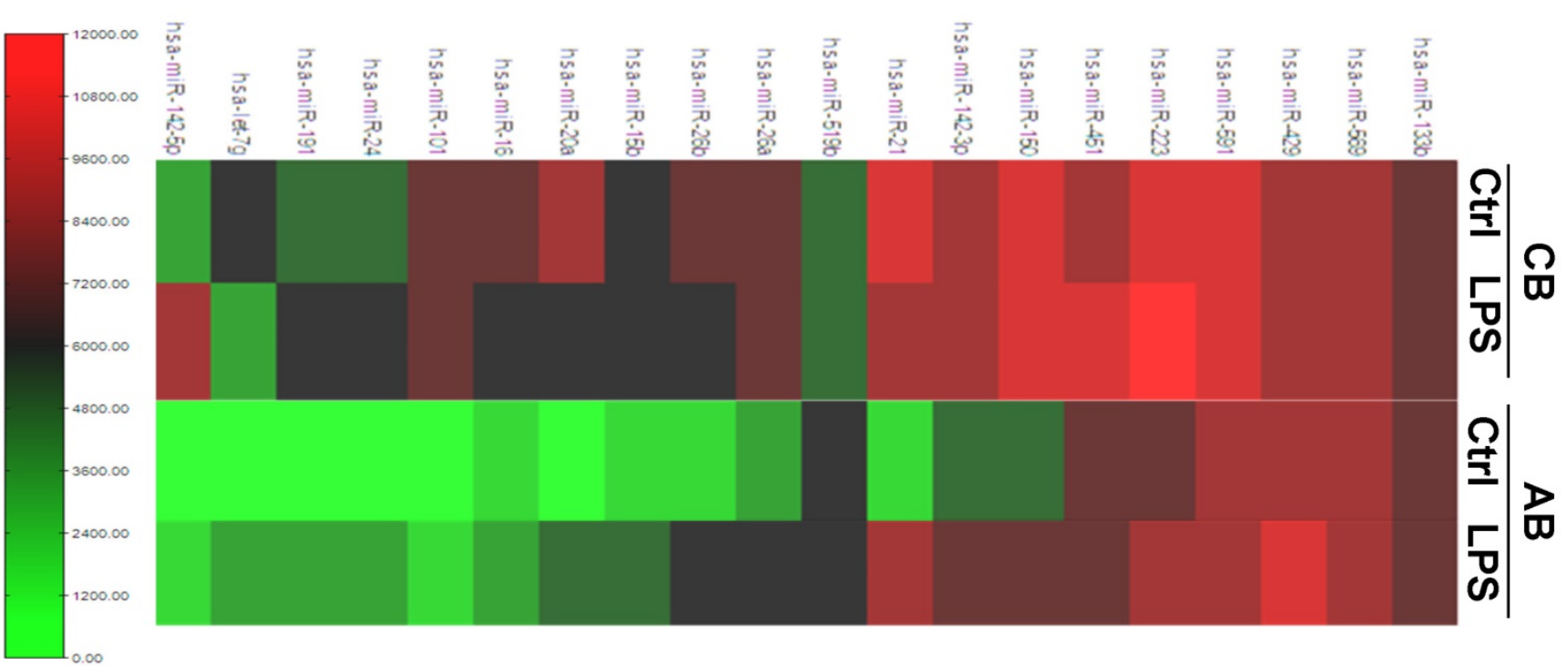

Figure 3. Profile of miRNAs related to IL-6. (A) Computational prediction of hsa-miRNAs targeting IL-6 3'-UTR by the miRanda, MicroCosm and TargetScan. The hsa-miR-142-3p, but not mmu-142-3p, was not predicted by all 3 programs. (B) Clustering of miRNA array expression between cord blood (CB) and adult blood (AB) without $(\mathrm{Ctrl})$ and with LPS treatment for $4 \mathrm{~h}$ was done by unsupervised hierarchical clustering using Manhattan hierarchical cluster metric from Illumina Genome Studio version 3.1.3.0.

\section{Discussion}

microRNAs are involved in the regulation of innate immune response [11]. This study provides a novel insight into neonatal PMN which expressed higher IL-6 protein and mRNA level after LPS stimulation than adult ones. And it was regulated by miR-142-3p and let-7g at the post-transcriptional level, not by a longer mRNA half-life after LPS stimulation in CB PMN. The modulation of IL-6 expression by miR-142-3p and let-7g may be useful in the regulation of neonatal inflammatory disorders. 
A

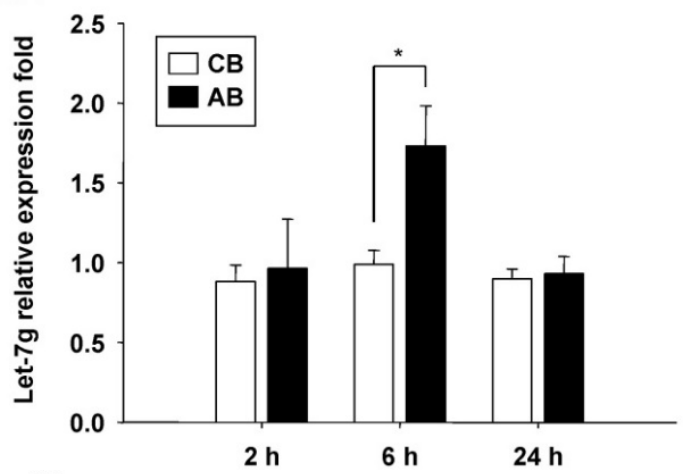

B

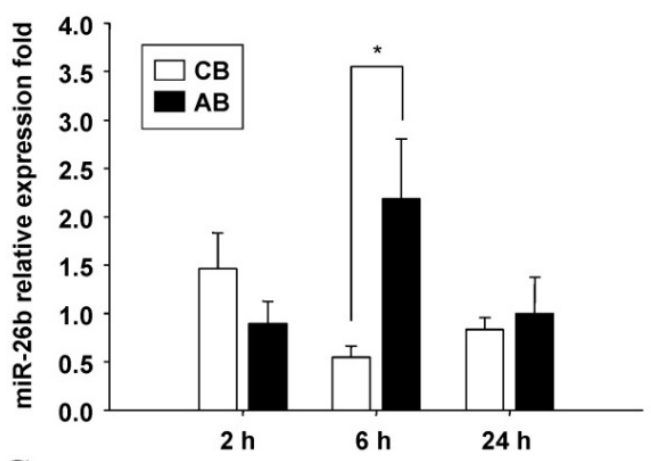

C

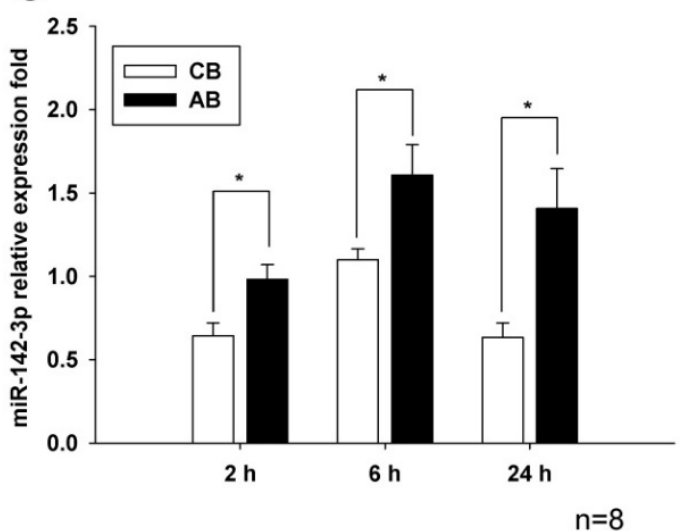

D

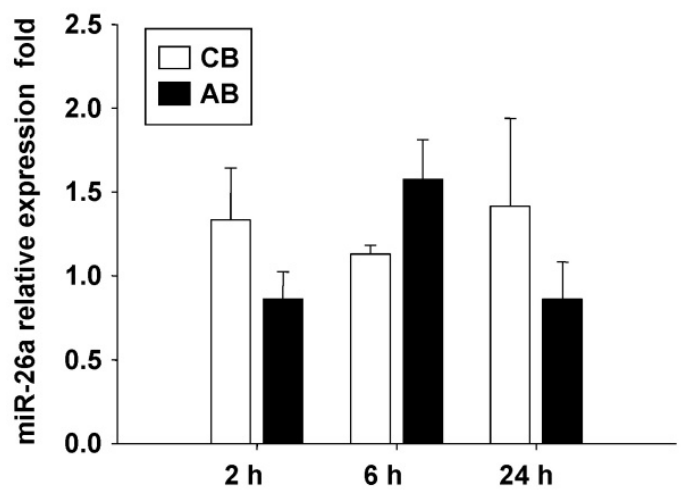

Figure 4. Verification of Illumina array results with qRT-PCR for four miRNAs. $C B$ and $A B$ PMN were stimulated with $100 \mathrm{ng} / \mathrm{mL}$ of LPS for indicated time. Cells were collected and indicated for (A) let-7g, (B) miR-26b, (C) miR-142-3p, and (D) miR-26a detection with qRT-PCR. The data shown are mean \pm SEM from 4-8 independent experiments. $*$ denotes $p<0.05$
We used three prediction software programs to detect potential miRNAs that may target IL-6 expression. Fifteen miRNAs predicted to be related to the regulation of IL- 6 gene expression were found at least in one of the 3 algorithms. These results were integrated with our bead array data. Using qRT-PCR, verification of let-7g, miR-26a, miR-26b, and miR-142-3p were performed along with the discovery of let-7g, miR-26b and miR-142-3p that had significantly changed post LPS stimulation. Thus, their mimics were chosen to transfect into cord and adult PMN to validate their functions. We found that miR-142-3p is only predicted by one program, but was involved in IL-6 mRNA and protein expression by neonatal PMN after LPS-stimulation. In fact, miR-142-3p had been demonstrated to regulate LPS-induced endogenous expression of IL-6 in a mouse model [10]. In contrast, two miRNAs (let-7g and let-7i) were predicted to target IL-6 expression by all the 3 algorithms. But only let-7g had prominent signal intensity changed in the array. This study also suggests that using 3 prediction databases to choose target miRNAs may be needed to explore the target miRNAs that regulate the expression of cytokines in different tissues.

In this study, Illumina BeadChip miRNA array was used instead of Agilent SurePrint human miRNA microarray chips, which revealed insignificant change of let-7 $\mathrm{g}$ and miR-142-3p in cord and adult PMN post LPS treatment in our previous study [12]. Although different microarray caused different result, nevertheless, the qRT-PCR data could reproduced the trend of the Illumina chip results (Fig. 3B, 4A and 4C). After LPS stimulation for $2 \mathrm{~h}$, level of miR-142-3p decreased in cord PMN, then increased in $6 \mathrm{~h}$, and decreased again in $24 \mathrm{~h}$. On the contrary, it increased in adult PMN in $6 \mathrm{~h}$ and $24 \mathrm{~h}$ post LPS stimulation (Fig. 4C). It might explains miR-142-3p repressed mRNA with the highest IL-6 mRNA found in cord PMN after LPS stimulation for $4 \mathrm{~h}$, thereafter, decreasing its level in $24 \mathrm{~h}$. Moreover, level of let-7g was unchanged in cord PMN as compared to adult PMN (increased almost 2 fold) post LPS stimulation. Collectively, higher level of miR-142-3p and let-7g in adult PMN versus limited changed of miR-142-3p and unchanged of let-7g in cord PMN post LPS stimulation explain the negative modulation of these miRNAs on higher IL-6 mRNA and protein in cord as compared to adult PMN post LPS stimulation.

Our functional study of transfection of let-7g mimics suppressed IL-6 expression post LPS stimulation in PMN was consistent with the result done in human umbilical vein endothelial cells [13]. Intriguingly, the miR-142-3p and let-7g mimics repressed IL-6 mRNA and protein more significantly 
in cord than in adult PMN. This might be that endogenous miRNAs were lower in cord than adult PMN post LPS stimulation, and the gain-of function of transfection of miRNA mimics might noticeably increase the level of miRNAs that were lower in CB, which in turn repressed more IL-6 in cord than adult PMN.
A

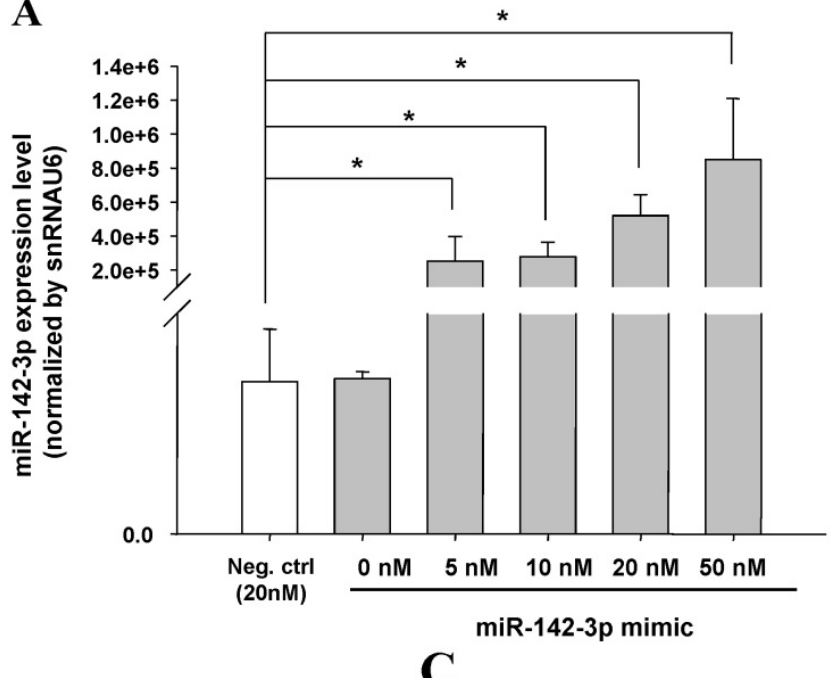

B

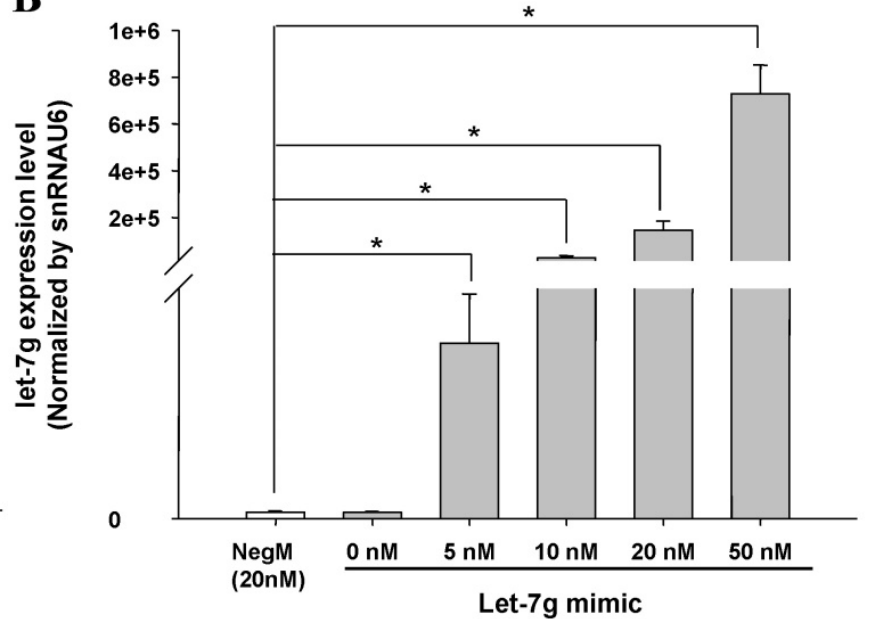$$
\text { C }
$$
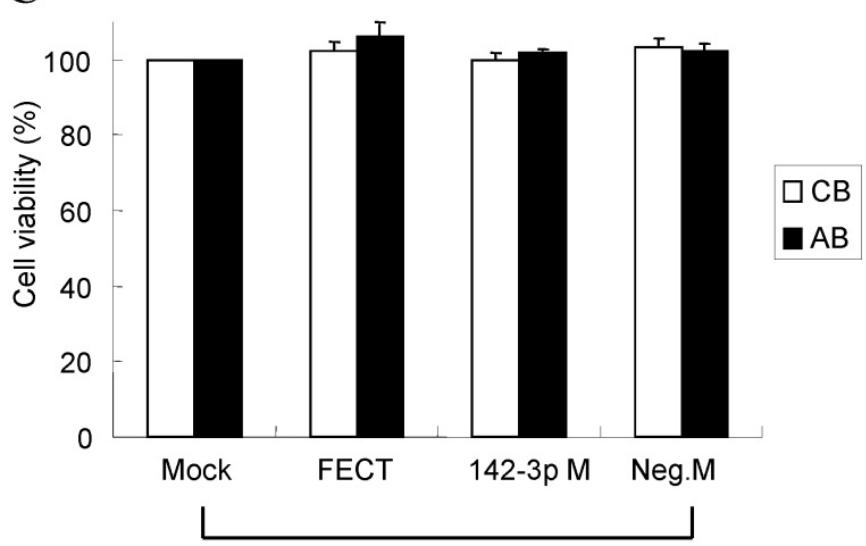

$\mathrm{AB}$

LPS stimulated $24 \mathrm{~h}$

D

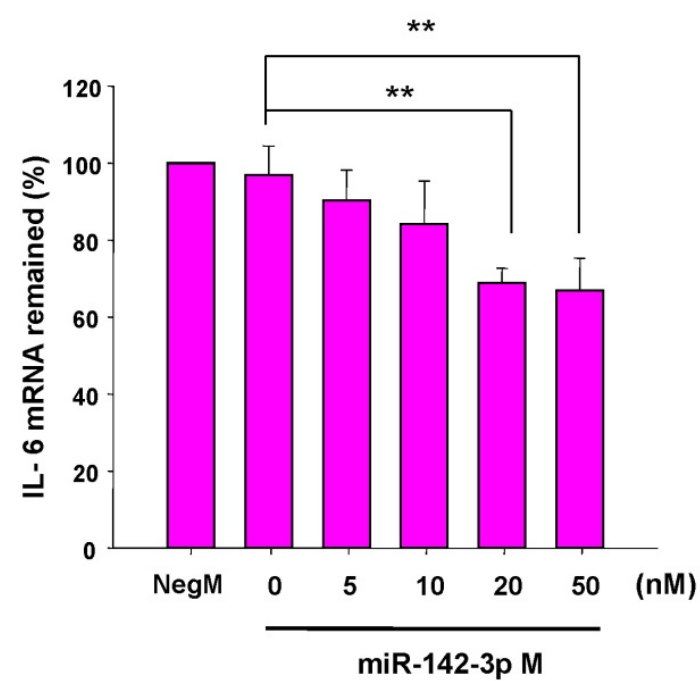

$A B$

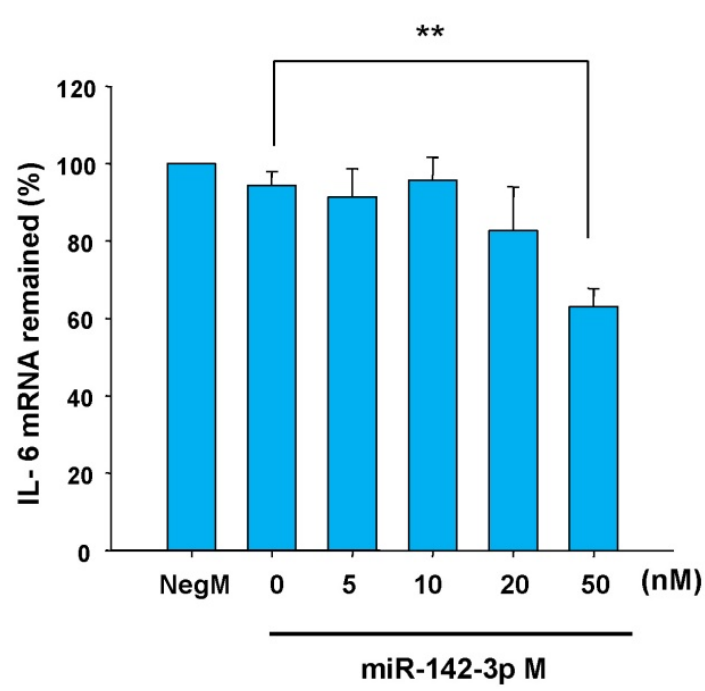


$\mathbf{E}$

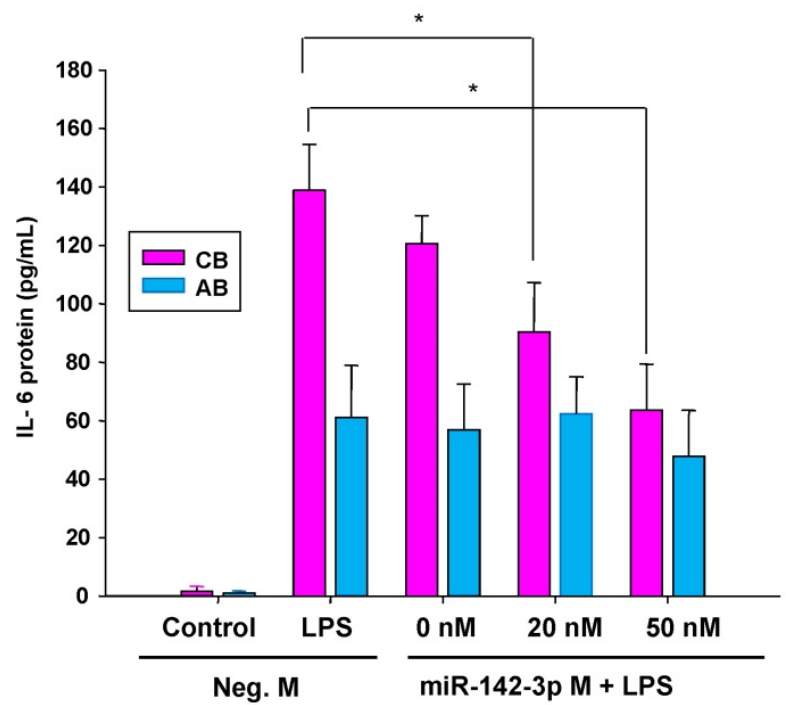

F

CB

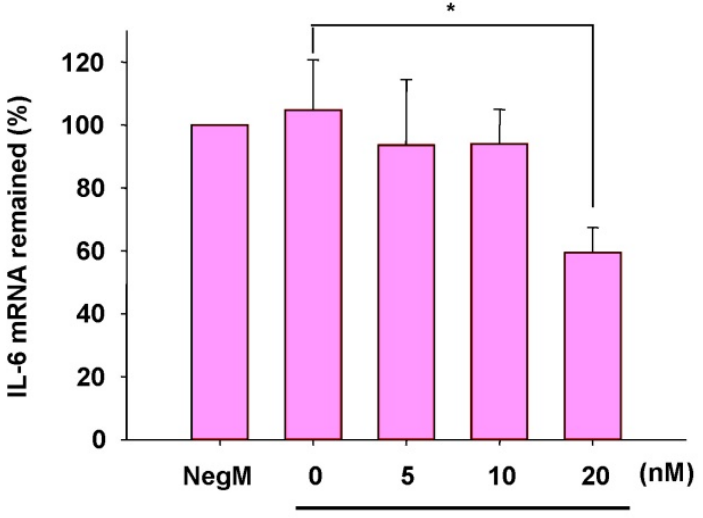

Let-7g M
$A B$

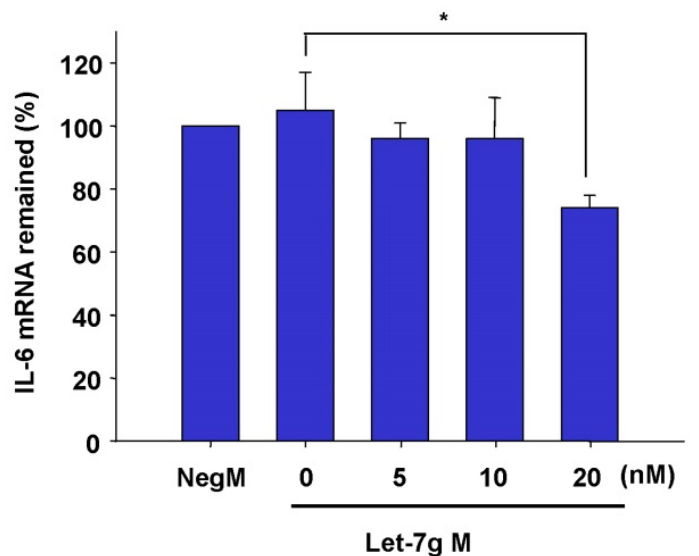

G

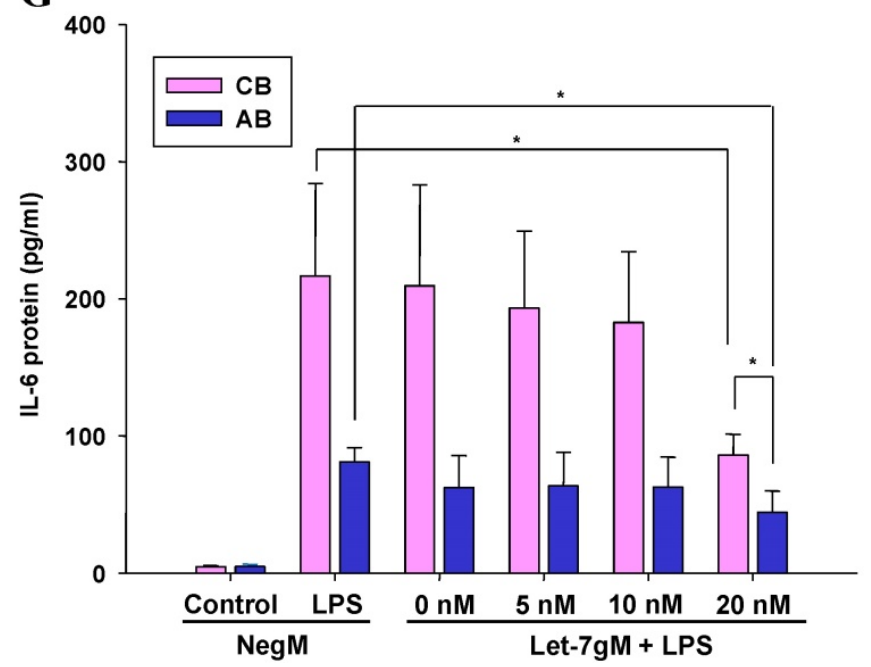

Figure 5. miR-142-3p and let-7g precursors supressed IL-6 mRNA and protein expression in cord blood (CB) and adult blood (AB) PMN. Indicated concentrations of (A) miR-142-3p mimics or (B) let-7g mimics or negative control (neg. ctrl) mimics were transfected into two CB and two AB PMN to study the effectiveness of the transfection. After CB and AB PMN were transfected with miR-142-3p mimics for $24 \mathrm{~h}$, then they were stimulated with LPS for $24 \mathrm{~h}$. (C) Their viability in culture media (mock), transfection media (FECT), miR-142-3p mimics (142-3p M) and negative control mimics (neg. M) were analysed by CCK-8. Indicated concentrations of miR-142-3-p mimics (M), let-7g mimics (M), or negative control mimics (neg. ctrl $M ; 20 \mathrm{nM}$ ) were transfected into $C B$ and $A B$ PMN for $24 \mathrm{~h}$, then stimulated with $100 \mathrm{ng} / \mathrm{mL}$ of LPS for another $24 \mathrm{~h}$. Cell pellets were collected from miR-142-3p M (D) or let-7g M (E) transfection and then indicated for IL-6 mRNA detection with qRT-PCR and the supernatant of miR-142-3p M (F) or let-7g $M(G)$ were analyzed by ELISA for IL-6 protein concentration. The data shown are from 4-5 independent experiments. * denotes $p<0.05, * *$ denotes $p<0.01$. 
Study had shown controversial on over or under expression of IL-6 by neutrophils [14]. In our results, IL-6 protein expression after LPS stimulation in AB was relatively low and appeared at $24 \mathrm{~h}$, whereas its mRNA was not detectable before LPS stimulation and expressed only after stimulation, which was in accordance with other studies $[15,16]$. Interestingly, CB expressed high IL-6 mRNA and protein post LPS stimulation, which might demonstrates that neonatal PMN preserving endotoxin-induced IL-6, a cytokine with pro and anti-inflammation and Th2-polarizing activities. High IL-6 in cord blood predicted sepsis and cerebral white matter damage in neonates $[4,17$, 18], higher IL-6 in neonatal monocytes after ex vivo LPS stimulation had been demonstrated as compared to adult [19-21]. Neonates are susceptible to infections; it has traditionally been attributed to the immaturity of their immune system. The functions of their PMNs are quantitatively and qualitatively impaired [22]. Our research on cellular level adds new insight into that aside neonatal monocytes, and their PMN also expressed higher IL-6 mRNA and protein than adult ones after LPS stimulation. From the observations described above, it can be concluded that neonatal leukocytes exhibit altered inflammatory reaction which produced high IL-6 that might cause severe disease morbidity.

miR-142-3p involved in cancer [23-26], infection [27], heart disease [28] and obesity [29, 30], whereas let-7g involved heavily in cancer [31, 32], vascular disease [13, 33] and obesity [34]. To date, the role of these 2 miRNAs in PMN are still underexplored. Our results unravel the involvement of miR-142-3p and let-7g in the post-transcriptional regulation of LPS-induced augmented IL-6 production in neonatal PMNs. And role of miR-142-3p was more effective than let-7 on IL-6 suppression in neonatal PMN. The modulation of miRNA expression may be used to regulate abnormal proinflammatory reaction in newborns.

\section{Materials and Methods}

\section{Collection and isolation of PMN from human umbilical cord blood and adult peripheral blood}

Human umbilical cord blood was collected into heparinized tubes $(10 \mathrm{U} / \mathrm{mL})$ by cordocentesis at the time of normal spontaneous delivery or elective Caesarean section of term newborns to healthy mothers, after informed consents were obtained. The peripheral blood samples were collected from healthy adult volunteers aged 25 to 40 years. Peripheral blood and umbilical cord blood were subjected to dextran $(4.5 \%)$ sedimentation at a ratio of $1: 5$ to separate leukocytes from red blood cells. Leukocytes were further separated into PMN and mononuclear cells by density gradient centrifugation in Ficoll-Paque ${ }^{\mathrm{TM}}$ PLUS (GE, Health care Bio-science AB) at a ratio of 2:1, as previously described [35]. All blood samples obtained were processed within $2 \mathrm{~h}$. The Institutional Review Board of the study hospital approved the study protocol.

\section{Cell culture and IL-6 induction}

Cord blood PMN (CB PMN) or adult peripheral blood PMN (AB PMN) were suspended at $1 \times 10^{6}$ cells/mL in RPMI-1640 medium (Gibco Laboratories, Grand Island, NY) containing 10\% heat-inactivated fetal bovine serum. $\mathrm{CB}$ PMN and $\mathrm{AB}$ PMN were stimulated with/without $100 \mathrm{ng} / \mathrm{mL}$ of LPS in 24-well culture plates with a total solution of $0.5 \mathrm{~mL}$ in a humidified atmosphere of $5 \% \mathrm{CO}_{2}$ at $37^{\circ} \mathrm{C}$. The cell pellets and culture supernatants were collected at indicated time and analyzed IL-6 mRNA expression with qRT-PCR or IL-6 protein production with ELISA (eBioscience, San Diego, CA), respectively. The LPS used was from purified Escherichia coli 055:B5 (Sigma-Aldrich, Inc., St. Louis, USA).

\section{Immunocytochemistry}

The immunohistochemistry of freshly purified PMN prepared in $1.5 \times 10^{4}$ cells/slide was performed using the stain kit Dako REALTM EnVision ${ }^{\mathrm{TM}}$ Detection System-DAB (\#K5007) following the manufacturer's protocol. The primary antibodies were rabbit polyclonal antibodies against human IL-6 purchased from Abcam (Cambridge, UK). In brief, the samples were incubated at $4^{\circ} \mathrm{C}$ overnight with the primary antibodies diluted 250 fold in Dako REAL ${ }^{\mathrm{TM}}$ antibody diluent, and then incubated with labeled polymer-HRP for $30 \mathrm{~min}$, and substrate-chromogen solution for 5-10 min. For the negative controls, the samples were treated using the same method with the exception that they were incubated with the antibody diluents instead of the primary antibodies. The nuclei were counterstained with Mayer's hematoxylin and mounted with xylene based mounting medium. The images of the PMN were captured by using Zeiss Axiovert 200 microscope (Germany). Aperture of the objective lenses was $10 \times / 0.35$, WD $70 \mathrm{~mm}$, temperature was $25^{\circ} \mathrm{C}$, original magnification was 400 fold, with AxioCam ICC3 camera (Carl Zeiss), and the acquisition software was AxioVision Rel.4.8.

\section{Reverse transcription (RT)-polymerase chain reaction (PCR) of IL-6 and 185 mRNAs}

Total cellular RNA was extracted using TRIzol Reagent (Invitrogen, Carlsbad, CA, USA) according to the manufacturer's instruction. RNA pellets were dissolved in diethypyrocarbonate-treated water and 
stored at $-20^{\circ} \mathrm{C}$ until use. A total of $20 \mathrm{ng}$ of RNA was subjected to reverse transcription for $60 \mathrm{~min}$ at $42^{\circ} \mathrm{C}$. The reverse-transcribed cDNA products were subjected to PCR amplification with specific primers and SYBR GREEN master mix quantification for amplifying two different transcripts, as follows:

(i) IL-6: forward primer 5' - ATG CAA TAA CCA CCC CTG AC-3' and reverse primer 5'-GAG GTG CCC ATG CTA CAT TT-3',

(ii) 18S: forward primer 5'-GTA ACC CGT TGA ACC CCA TT-3' and reverse primer 5'-CCA TCC AAT CGG TAG TAG CG-3’.

The PCR steps were activated by heating for 10 min at $95^{\circ} \mathrm{C}$ for 1 cycle, then for $15 \mathrm{~s}$ at $95^{\circ} \mathrm{C}$, and finally for $60 \mathrm{~s}$ at $60^{\circ} \mathrm{C}$ for 40 cycles in a PCR mix containing $2 \mu \mathrm{L}$ of the cDNA template, $0.5 \mu \mathrm{L}$ of 10 $\mu \mathrm{M}$ primer, and $5 \mu \mathrm{L}$ of SYBR GREEN master mix in a total volume of $20 \mu \mathrm{L}$. The system generated a kinetic amplification plot based on the normalized fluorescence. These PCR experiments included a negative control without a template to ensure absence of contamination. All reactions were performed in triplicate in an ABI 7500 sequence detection system (Applied Biosystems, Perkin-Elmer, Foster City, CA) [36].

\section{Transcriptional and post-transcriptional mechanisms of LPS-stimulated IL-6 production}

PMN in $1 \times 10^{6} / \mathrm{mL}$ were treated with 100 $\mathrm{ng} / \mathrm{mL}$ of LPS for $4 \mathrm{~h}$, then treated or not with 1 $\mu \mathrm{g} / \mathrm{mL}$ of Act D or $5 \mu \mathrm{g} / \mathrm{mL}$ of CHX for the indicated time. PMN from the reactions with and without Act D or CHX were subjected to total RNA extraction by the TRIzol reagent. The degrading time of IL-6 mRNA expression after Act $\mathrm{D}$ treatment is inferred to de novo transcriptional level, whereas IL-6 mRNA expression after $\mathrm{CHX}$ treatment is inferred to post-transcriptional regulation [37].

\section{Detection of miRNAs expression profiling panels by Illumina bead array}

MicroRNAs from cord or adult PMN cells with or without LPS stimulation for $4 \mathrm{~h}$ were measured by BeadChip miRNA expression assay (PAS; Illumina) as previously described according to the manufacturer's protocol. The Illumina BeadArray ${ }^{\mathrm{TM}}$ Reader detected 470 miRNAs as described in the miRBase database v9.1 and measured the signal intensity at each address location which corresponded to the quantity of the respective miRNA in the original sample. Results of the miRNA array were evaluated for their signal intensity and the 2-fold decrease or increase after LPS stimulation between neonatal and adult PMN cells were selected and integrated with miRNA prediction software program. The results were further validated by real-time quantitative RT-PCR.

\section{Measurement of miRNA expression by RT-PCR}

Various miRNAs expression were detected with the TaqMan ${ }^{\circledR}$ microRNA Reverse Transcription Kit, TaqMan ${ }^{\circledR}$ MicroRNA Primer Assays kit and TaqMan ${ }^{\circledR}$ 2X Universal PCR Master Mix (Applied Biosystem, Foster City, CA), in accordance with the manufacturer's instructions. Expression of snRNAU6 was used as an internal control. Reverse transcription was carried out on $20 \mathrm{ng}$ of total RNA in $15 \mu \mathrm{L}$ reactions using the TaqMan ${ }^{\circledR}$ MicroRNA Reverse Transcription Kit (Applied Biosystems, Foster City, $\mathrm{CA}$ ), each RT-PCR reactions included $30 \mathrm{~min}$ at $16^{\circ} \mathrm{C}$, $30 \mathrm{~min}$ at $42^{\circ} \mathrm{C}$, and $5 \mathrm{~min}$ at $85^{\circ} \mathrm{C}$ according to the manufacturer's instructions. Using an Applied Biosystems 7500 quantitative real-time PCR machine (Applied Biosystems, Perkin-Elmer, Foster City, CA), $20 \mu \mathrm{L}$ real-time PCR reactions were carried out on 1 $\mu \mathrm{L}$ of cDNA using TaqMan ${ }^{\circledR}$ Universal PCR Master Mix (Applied Biosystems). Each real-time PCR reactions included $10 \mathrm{~min}$ at $95^{\circ} \mathrm{C}$ for one cycle, $15 \mathrm{~s}$ at $95^{\circ} \mathrm{C}$, and $1 \mathrm{~min}$ at $60^{\circ} \mathrm{C}$ for 40 cycles, in accordance with the manufacturer's instructions. The comparative threshold of PCR cycles (cycle threshold, $\mathrm{Ct}$ ) value was used to calculate the relative miRNA expression. The amount of each miRNA (from cord or adult PMN with or without LPS stimulation) relative to snRNAU6 was calculated using the equation, $2^{-\Delta(\mathrm{Ct})}$, where $\Delta(\mathrm{Ct})=\left(\mathrm{Ct}_{\text {miRnA }}-\mathrm{Ct}_{\text {snRNAU6 }}\right)$, method was used to determine relative-quantitative levels of individual miRNAs, and these were expressed as the fold-difference to the study/control condition, as previously described [38].

\section{Gain-of-function experiments with miRNA precursor transfection into PMN}

Specific let-7g, miR-142-3p, or miR-26b miR-precursor molecules (Thermo scientific Dharmacon, miRDIA, mimic) and negative control precursor miRNAs were transfected into PMN at different final concentrations of 5 to $50 \mathrm{nM}$ using FECT transfection reagent (Thermo scientific Dharmacon) as indicated. PMN in $5 \times 10^{5}$ cells $/ \mathrm{mL}$ were cultured in RPMI-1640 medium supplemented with $10 \%$ fetal bovine serum and the transfection medium was added for transfection of miRNA mimic for $24 \mathrm{~h}$. The transfection medium was prepared from the mixture of miRNA mimic medium and DharmaFECT medium with serum-free RPMI 1640 medium to a final volume of $500 \mu \mathrm{L}$, according to the manufacturer's instructions. The transfected PMN were then stimulated with LPS $(100 \mathrm{ng} / \mathrm{mL})$ for $24 \mathrm{~h}$ 
in replaced RPMI-1640 medium and were supplemented with $10 \%$ fetal bovine serum. The let-7g, miR-142-3p, miR-26b or IL-6/18S mRNA expression from harvested PMN were measured by qRT-PCR. Culture supernatants were collected and then indicated for IL-6 protein detection with ELISA.

To optimize an efficient transfection, cell proliferation and cytotoxicity assay were performed by cell counting kit-8 (CCK-8), (Dojindo technical). In brief, $5 \times 10^{4}$ cells per $100 \mu \mathrm{L}$ medium were cultured in a 96 well-plate supplemented with $10 \mu \mathrm{L}$ of CCK-8 solution. After incubation for $2 \mathrm{~h}$, we measured the absorbance at $450 \mathrm{~nm}$ by a microplate reader.

\section{Statistics}

Data were expressed as mean \pm SEM. The statistical calculation was performed with Mann-Whitney $U$-test. Results with a $p$-value of less than 0.05 were considered statistically significant. All statistical tests were performed using SPSS software.

\section{Abbreviations}

AB: adult blood; Act-D: actinomycin D; CB: cord blood; CHX: cycloheximide; Ctrl: control; hsa: homo sapiens; M: mimics; miR-23a: microRNA-23a-3p; miR-23b: microRNA-23b-3p; miR-26a: microRNA-26a-5p; miR-26b: microRNA-26b-5p; mmu: Mus musculus; let-7a: let-7a-5p; let-7d: let-7d-5p; let-7e: let-7e-5p; let-7f: let-7f-5p; let-7g: let-7g-5p; let-7f: let-7f-5p; let-7i: let-7i-5p

\section{Acknowledgments}

This study was supported in part by grant CMRPG 8C1361 (H-Chun Huang), CLRPG8B0053, CZRPG880253 from Chang Gung Memorial Hospital-Kaohsiung Medical Center, Kaohsiung; grants 102-2314-B-182A-045 (H-Chun Huang) and 099-2811-B-182-018 (KD Yang) from the Ministry of Science and Technology, Taiwan. We thank our colleagues from stem cell research core laboratory who provided insight and expertise that greatly assisted the research.

\section{Competing Interests}

The authors have declared that no competing interest exists.

\section{References}

1. Stoll BJ, Hansen NI, Sanchez PJ, Faix RG, Poindexter BB, Van Meurs KP, et al. Early onset neonatal sepsis: the burden of group B Streptococcal and E. coli disease continues. Pediatrics. 2011; 127: 817-26.

2. Dammann $\mathrm{O}$, Leviton $\mathrm{A}$. Maternal intrauterine infection, cytokines, and brain damage in the preterm newborn. Pediatr Res. 1997; 42: 1-8.

3. Gomez R, Romero R, Ghezzi F, Yoon BH, Mazor M, Berry SM. The fetal inflammatory response syndrome. Am J Obstet Gynecol. 1998; 179: 194-202.

4. Krueger M, Nauck MS, Sang S, Hentschel R, Wieland H, Berner R. Cord blood levels of interleukin-6 and interleukin- 8 for the immediate diagnosis of early-onset infection in premature infants. Biol Neonate. 2001; 80: 118-23.
5. Hsu BG, Lee RP, Yang FL, Harn HJ Chen HI Post-treatment with $\mathrm{N}$-acetylcysteine ameliorates endotoxin shock-induced organ damage in conscious rats. Life sci. 2006; 79: 2010-6.

6. Kishimoto T, Akira S, Narazaki M, Taga T. Interleukin-6 family of cytokines and gp130. Blood. 1995; 86: 1243-54.

7. Jones SA. Directing transition from innate to acquired immunity: defining a role for IL-6. J Immunol. 2005; 175: 3463-8.

8. Choy EHS, Isenberg DA, Garrood T, Farrow S, Ioannou Y, Bird H, et al. Therapeutic benefit of blocking interleukin-6 activity with an anti-interleukin-6 receptor monoclonal antibody in rheumatoid arthritis: a randomized, double-blind, placebo-controlled, dose-escalation trial. Arthritis Rheum. 2002; 46: 3143-50.

9. Ito H, Takazoe M, Fukuda Y, Hibi T, Kusugami K, Andoh A, et al. A pilot randomized trial of a human anti-interleukin- 6 receptor monoclonal antibody in active Crohn's disease. Gastroenterology. 2004; 126: 989-96.

10. Sun Y, Varambally S, Maher CA, Cao Q, Chockley P, Toubai T, et al. Targeting of microRNA-142-3p in dendritic cells regulates endotoxin-induced mortality. Blood. 2011; 117: 6172-83

11. Taganov KD. NF-кB-dependent induction of microRNA miR-146, an inhibitor targeted to signaling proteins of innate immune responses. Proc. Natl. Acad. Sci. USA. 2006; 103: 12481-6.

12. Yu H-R, Hsu T-Y, Huang H-C, Kuo H-C, Li S-C, Yang KD, et al. Comparison of the functional microRNA expression in immune cell subsets of neonates and adults. Front. Immunol. 2016; 7:615.

13. Liao YC, Wang YS, Guo YC, Lin WL, Chang MH, Juo SH. Let-7g improves multiple endothelial functions through targeting transforming growth factor-beta and SIRT-1 signaling. J Am Coll Cardiol. 2014; 63: 1685-94.

14. Cassatella MA. The production of cytokines by polymorphonuclear neutrophils. Immunol Today. 1995; 16: 21-6.

15. Altstaedt J, Kirchner H, Rink L. Cytokine production of neutrophils is limited to interleukin-8. Immunology. 1996; 89: 563-8.

16. Schroder AK, von der Ohe M, Kolling U, Altstaedt J, Uciechowski P, Fleischer $\mathrm{D}$, et al. Polymorphonuclear leucocytes selectively produce anti-inflammatory interleukin-1 receptor antagonist and chemokines, but fail to produce pro-inflammatory mediators. Immunology. 2006; 119: 317-27.

17. Yoon BH, Romero R, Yang SH, Jun JK, Kim IO, Choi JH, et al. Interleukin-6 concentrations in umbilical cord plasma are elevated in neonates with white matter lesions associated with periventricular leukomalacia. Am J Obstet Gynecol. 1996; 174: 1433-40.

18. Santana C, Guindeo MC, González G, García-Muñoz F, Saavedra P, Doménech E. Cord blood levels of cytokines as predictors of early neonatal sepsis. Acta Pædiatr. 2001; 90: 1176-81.

19. Schultz C, Rott C, Temming P, Schlenke P, Moller JC, Bucsky P. Enhanced interleukin- 6 and interleukin-8 synthesis in term and preterm infants. Pediatr Res. 2002; 51: 317-22.

20. Angelone DF, Wessels MR, Coughlin M, Suter EE, Valentini P, Kalish LA, et al. Innate immunity of the human newborn is polarized toward a high ratio of IL-6/TNF-alpha production in vitro and in vivo. Pediatr Res. 2006; 60: 205-9.

21. Kollmann TR, Crabtree J, Rein-Weston A, Blimkie D, Thommai F, Wang XY, et al. Neonatal innate TLR-mediated responses are distinct from those of adults. J Immunol. 2009; 183: 7150-60.

22. Koenig JM, Yoder MC. Neonatal neutrophils: the good, the bad, and the ugly. Clin Perinatol. 2004; 31: 39-51.

23. Kaduthanam S, Gade S, Meister M, Brase JC, Johannes M, Dienemann H, et al. Serum miR-142-3p is associated with early relapse in operable lung adenocarcinoma patients. Lung cancer (Amsterdam, Netherlands). 2013; 80: 223-7.

24. Lin RJ, Xiao DW, Liao LD, Chen T, Xie ZF, Huang WZ, et al. MiR-142-3p as a potential prognostic biomarker for esophageal squamous cell carcinoma. J Surg Oncol. 2012; 105: 175-82

25. Shen WW, Zeng Z, Zhu WX, Fu GH. MiR-142-3p functions as a tumor suppressor by targeting CD133, ABCG2, and Lgr5 in colon cancer cells. J Mol Med (Berlin, Germany). 2013; 91: 989-1000.

26. Wang F, Wang XS, Yang GH, Zhai PF, Xiao Z, Xia LY, et al. miR-29a and miR-142-3p downregulation and diagnostic implication in human acute myeloid leukemia. Mol Biol Rep. 2012; 39: 2713-22.

27. Kleinsteuber K, Heesch K, Schattling S, Kohns M, Sander-Julch C, Walzl G, et al. Decreased expression of miR-21, miR-26a, miR-29a, and miR-142-3p in CD4(+) T cells and peripheral blood from tuberculosis patients. PLoS One. 2013; 8: e61609.

28. Ellis KL, Cameron VA, Troughton RW, Frampton CM, Ellmers LJ, Richards AM. Circulating microRNAs as candidate markers to distinguish heart failure in breathless patients. Eur J Heart Fail. 2013; 15: 1138-47.

29. Ortega FJ, Mercader JM, Catalan V, Moreno-Navarrete JM, Pueyo N, Sabater $\mathrm{M}$, et al. Targeting the circulating microRNA signature of obesity. Clin Chem. 2013; 59: 781-92.

30. Prats-Puig A, Ortega FJ, Mercader JM, Moreno-Navarrete JM, Moreno M, Bonet $\mathrm{N}$, et al. Changes in circulating microRNAs are associated with childhood obesity. J Clin Endocrinol Metab. 2013; 98: E1655-60.

31. Oztemur Y, Bekmez T, Aydos A, Yulug IG, Bozkurt B, Dedeoglu BG. A ranking-based meta-analysis reveals let-7 family as a meta-signature for grade classification in breast cancer. PLoS One. 2015; 10: e0126837.

32. Nakajima G, Hayashi K, Xi Y, Kudo K, Uchida K, Takasaki K, et al. Non-coding microRNAs hsa-let-7g and hsa-miR-181b are associated with 
chemoresponse to S-1 in colon cancer. Cancer genomics \& proteomics. 2006; 3: 317-24.

33. Zhang Y, Chen N, Zhang J, Tong Y. Hsa-let-7g miRNA targets caspase-3 and inhibits the apoptosis induced by ox-LDL in endothelial cells. Int J Mol Sci. 2013; 14: 22708-20.

34. Yan X, Huang Y, Zhao J-X, Rogers CJ, Zhu M-J, Ford SP, et al. Maternal obesity down-regulates microRNA (miRNA) let-7g expression, a possible mechanism for enhanced adipogenesis during ovine fetal skeletal muscle development. Int J Obes. 2013; 37: 568-75.

35. Yu HR, Chen RF, Hong KC, Bong CN, Lee WI, Kuo HC, et al. IL-12-independent Th1 polarization in human mononuclear cells infected with varicella-zoster virus. Eur J Immunol. 2005; 35: 3664-72.

36. Chen RF, Huang HC, Ou CY, Hsu TY, Chuang H, Chang JC, et al. MicroRNA-21 expression in neonatal blood associated with antenatal immunoglobulin E production and development of allergic rhinitis. Clin Exp Allergy. 2010; 40: 1482-90.

37. Huang H-C, Tai F-Y, Wang F-S, Liu C-A, Hsu T-Y, Ou C-Y, et al. Correlation of augmented IL-8 production to premature chronic lung disease: Implication of posttranscriptional regulation. Pediatr Res. 2005; 58: 216-21.

38. Huang H-C, Yu H-R, Huang L-T, Huang H-C, Chen R-F, Lin IC, et al. miRNA-125b regulates TNF- $a$ production in CD14+ neonatal monocytes via post-transcriptional regulation. J Leukoc Biol. 2012; 92: 171-82. 